\title{
PROPOSTA METODOLÓGICA PARA A IDENTIFICAÇÃO DE SUBCENTROS URBANOS: ESTUDO DE CASO NA REGIÃO METROPOLITANA DE SÃO PAULO
}

\author{
Luiz Paulo Ribeiro Siqueira *
}

\begin{abstract}
Resumo
A identificação formal de subcentros, em geral, é feita a partir de três tipos de procedimentos metodológicos distintos: estabelecimento de valores de corte, estimativas econométricas e a análise exploratória de dados espaciais, cada qual com seus méritos e deméritos próprios para a análise intra urbana. Contudo, em poucos trabalhos, a exemplo de McMillen \& Smith (2003) e McMillen \& Lester (2003), se busca a interlocução entre esses procedimentos com o intuito de aperfeiçoar os resultados e suplantar os pontos frágeis de cada abordagem metodológica. Com esse objetivo, se propõe um procedimento para identificação de subcentros de dois estágios, englobando duas das metodologias listadas, a saber: a análise exploratória de dados espaciais e o método de valores de corte. O local avaliado é a Região Metropolitana de São Paulo com base nos dados da Pesquisa Origem e Destino de 2007.
\end{abstract}

Palavras-chave: Identificação de subcentros; Descentralização do emprego; Região Metropolitana de São Paulo.

\begin{abstract}
The formal identification of sub-centers is made basically from the replica of three distinct types of methodological procedures, establishment of cutoff values, econometric estimates and exploratory analysis of spatial data, each with its own merits and demerits for intra-urban analysis. However, in a few works, like McMillen \& Smith (2003) and McMillen \& Lester (2003), there is a dialogue between the procedures in order to improve results and overcome the weaknesses of each methodological approach. With this goal, this paper proposes a two-stage procedure for identifying sub-centers, comprising two of the methods listed, namely: the exploratory analysis of spatial data and the cutoff values procedure. The subject site is the Metropolitan Region of São Paulo based on data from the Pesquisa Origem e Destino de 2007.
\end{abstract}

Keywords: Subcenters identficiation; Employment descentralization; Região Metropolitana de São Paulo.

JEL classification: R12, R30.

DOI: http : / /dx.doi.org/10.1590/1413-8050/ea476

* Pontifícia Universidade Católica de São Paulo. E-mail: lprsiqueira@gmail.com 


\section{Introdução}

A identificação de subcentros tornou-se prática relevante nos estudos urbanos na medida em que se observou a descentralização dos empregos, processo fruto da intensa suburbanização que ocorreu ao longo do século XX, tal como pontuam Glaeser \& Kahn (2001). A descentralização dos empregos, por sua vez, causa alterações significativas na estrutura tida como padrão para uma cidade, fazendo com que a abordagem monocêntrica, principal âncora nas análises econômico-urbanas, por exemplo, já não mais corresponda à realidade, Richardson (1997).

Devido a esse motivo, a partir da década de 1980 análises sob a perspectiva policêntrica do meio urbano ganharam corpo, seja em proposições teóricas, como no trabalho de Fujita \& Ogawa (1982), como em trabalhos de cunho empírico, a exemplo de McDonald (1987). Entretanto, e tal como apontam McMillen \& Smith (2003), ambas as abordagens desenvolveram-se em relativo isolamento, com os modelos teóricos focados na análise da configuração espacial de equilíbrio em cidades policêntricas e os empíricos na identificação de subcentros e sua influência na densidade do emprego, população e preço de imóveis.

Todavia, por conta do inferior poder de análise da abordagem teórica policêntrica, se comparada à monocêntrica, tal como pontuam Richardson (1997) e White (1999), nas últimas décadas grande parcela dos trabalhos se voltou à abordagem empírica, por meio da elaboração e réplica de diversos parâmetros e procedimentos metodológicos para a identificação de subcentros. Em meio a estes, três categorias de métodos ganharam maior destaque na prática internacional: o método de valores de corte, a análise econométrica e a Análise Exploratória de Dados Espaciais - AEDE, tal como pontuam López \& Muñiz (2005), Kneib (2008) e Siqueira (2012).

Muito embora cada um desses procedimentos metodológicos seja autossuficiente em seus objetivos, trabalhos como McMillen \& Lester (2003) e McMillen \& Smith (2003), sugerem que o uso conjunto de metodologias (nesse caso métodos econométricos e valores de corte) é capaz de apontar resultados mais robustos, se comparados à aplicação dos métodos de modo isolado.

Com base nessa linha de argumentação, assim sendo, este trabalho se debruçará sobre a proposição e teste de um procedimento de dois estágios que seja capaz de apontar resultados robustos no que diz respeito à localização, relevância e extensão dos subcentros identificados. Para alçar tais objetivos, o método proposto englobará em cada um dos estágios uma categoria de método diferente. No primeiro a AEDE, pelo intermédio de uma de suas ferramentas mais disseminadas - a estatística local I de Moran. Já no segundo, servindo como uma espécie de filtro aos resultados iniciais, serão aplicados valores de corte para duas variáveis: a densidade do emprego, vastamente utilizada na literatura, e a razão a qual chamaremos "E/PO", tal como utilizado em Coffey \& Shearmur (2001).

A análise conduzida, entretanto, além da especificação do método e seus componentes (seção 6), abordará de forma breve a questão do Problema de Unidade de Área Modificável - MAUP ${ }^{1}$ (seção 4), e avaliará também a descentralização do emprego no período 1997-2007 na RMSP, por meio da avaliação, por exemplo, de indicadores como o de distância ao centro ponderada

\footnotetext{
${ }^{1}$ Do inglês Modifiable Area Unit Problem.
} 
pela concentração do emprego - DPE, e o I de Moran Global (seção 5). Na parte final do trabalho (seção 7), após a apresentação dos resultados finais, será realizada, ainda, uma análise acerca da especialização dos empregos nos subcentros através do cálculo do quociente locacional - QL, como forma de demonstrar as diversas análises que podem ser feitas a partir da identificação de subcentros urbanos.

O restante do trabalho é composto pelo seguinte. A seção 2 apresenta a caracterização de um centro e um subcentro. A seção 3 faz a revisão acerca das principais metodologias para a identificação de subcentros e exposição de resultado de trabalhos. A seção 4, além da abordagem sobre o MAUP, também apresenta a base de dados principal, ou seja, a Pesquisa Origem e Destino do Metrô de 2007. Por fim, na seção 8, são feitos os comentários finais.

\section{Centros e Subcentros urbanos - caracterização}

O centro de uma cidade, ou sua área central, segundo Castells (1983), é o local que concentra as principais atividades comerciais, de serviços, da gestão pública e privada, além de terminais de transporte e construções verticais (prédios), permitindo a coordenação e ordenação das atividades e a comunicação entre os atores. Assim como expôs Castells, na literatura urbana, de modo geral, o centro distingue-se das demais localidades do meio urbano, pois possui um conjunto de características próprias e particulares que fazem dele um ponto distinto do espaço urbano, tal como a concentração de atividades, melhor infraestrutura de transportes (acessibilidade), maior valor dos imóveis e simbolismo, tal como aponta Kneib (2008).

Subcentros urbanos, por sua vez, foi o nome dado às novas centralidades que emergiram em meio ao processo de expansão urbana e descentralização do emprego e população, observado ao longo da segunda metade do século XX, principalmente nos EUA, tal como abordam Anas et al. (1998) e Glaeser \& Kahn (2001). Em grande parcela dos trabalhos de cunho urbano, os subcentros, para fins e efeitos, são tidos como verdadeiras miniaturas do centro principal. Villaça (1998), por exemplo, denomina como subcentro aglomerações diversificadas e equilibradas de comércio e serviços, que não o centro principal; ou ainda uma réplica, em tamanho menor do centro principal, com o qual concorrem em parte sem, entretanto, a ele se igualar.

Embora os estudos urbanos tendam a caracterizar os centros e subcentros urbanos como locais que possuam um conjunto de atributos, os que se propõe a estabelecer métodos para identificá-los, ou necessitam, para outros fins, estabelecer localizações urbanas centrais, no geral, buscam caracterizar estes locais a partir de apenas uma das características usualmente relacionadas, quer seja para atender aos objetivos específicos da pesquisa, ou pela complexa mensuração de certos atributos.

Principalmente nos estudos relacionados à Nova Economia Urbana — NEU, a característica que ao longo do tempo mais serviu à identificação dos centros e subcentros urbanos foi, e é, o nível de concentração das atividades, mensurada através de medidas relacionadas ao emprego. O uso de medidas relacionadas ao emprego como ponto determinante para a identificação das centralidades, na economia urbana e regional, remete às discussões sobre os efeitos gerados pelas economias de aglomeração, ${ }^{2}$ presente nas discussões clássicas

\footnotetext{
${ }^{2}$ As economias de aglomeração consistem em ganhos de produtividade que são atribuídos à
} 
de Marshall (1982), ou de forma mais específica para o meio urbano em Jacobs $(1969) .^{3}$

Dessa forma, como este trabalho vislumbra a proposição de um método para a identificação de subcentros, medidas relacionadas ao nível de concentração do emprego serão tomadas como proxys aos níveis das economias de aglomeração, ${ }^{4}$ em linha com o que se propõe, por exemplo, em McDonald \& McMillen (1998) e Coffey \& Shearmur (2001).

\section{Métodos para a identificação de subcentros}

Os métodos para a identificação de subcentros foram desenvolvidos com o intuito de possibilitar uma análise mais acurada da estrutura das grandes cidades e regiões metropolitanas policêntricas, jogando luz, principalmente, sobre o processo de descentralização do emprego, Greene (1980).

Embora modelos ligados à NEU com cenários de descentralização do emprego, ou seja, não monocêntricos, tenham sido publicados já a partir da década de 1970, tal como pontua White (1999), a identificação de subcentros até o início dos anos de 1980 deu-se sobremaneira pelo uso de localizações pré-estabelecidas por agências de planejamento, ou definições relacionadas à importância histórica de certas localidades como polos de crescimento, Giuliano \& Small (1991). A partir da metade final da década de 1980, contudo, ganhou força e corpo na prática internacional a identificação de subcentros por meio de métodos quantitativos, a exemplo do proposto por McDonald (1987), tido como a primeira metodologia formal para a identificação de subcentros, McMillen (2001a).

A análise extensiva dos trabalhos quantitativos voltados à identificação de subcentros que foram publicados ao longo das últimas décadas, tal como feita em López \& Muñiz (2005), Kneib (2008) ou Siqueira (2012), possibilita agrupar as metodologias utilizadas em pelo menos três categorias principais: valores de corte, econometria e AEDE, apresentadas na sequência, tal como se discutirá na sequência.

\subsection{As metodologias baseadas em valores de corte}

Os métodos baseados em valores de corte constituem a metodologia para identificação de subcentros mais disseminada na prática internacional. Em grandes linhas, tais procedimentos identificam os subcentros a partir do estabelecimento de limites inferiores (valores de corte) para variáveis que possam atribuir às localidades do meio intra urbano características de lugares centrais. Boa parte desses trabalhos, tal como ponderam Coffey \& Shearmur (2001) e López \& Muñiz (2005), utilizam dois parâmetros para corte: um para o total de trabalhadores e outro para a densidade do emprego. ${ }^{5}$

aglomeração geográfica das populações ou das atividades econômicas.

${ }^{3}$ É importante frisar que no âmbito das economias de aglomeração, Marshall (1982), dá maior destaque aos ganhos oriundos da especialização das atividades, enquanto Jacobs (1969) enfatiza que no meio urbano a mais relevante fonte de externalidades é a diversidade das atividades econômicas.

${ }^{4}$ Outras variáveis também utilizadas para mensurar as economias de aglomeração são, por exemplo, os anos de estudo e o nível dos salários.

${ }^{5}$ Embora esses dois parâmetros sejam os mais usuais, encontra-se na literatura o uso combinado com outras variáveis como o fluxo diário de viagens. 
Em meio a esse grupo de metodologias, uma das mais influentes na prática internacional foi a apresentada no trabalho de Giuliano \& Small (1991). Segundo esse procedimento, um subcentro seria definido como um conjunto de zonas contíguas, cada qual com densidade de emprego superior a algum valor de corte $D$ e que em conjunto possuíssem um total mínimo de empregos E. Nessa definição, o subcentro seria delimitado pela zona a partir da qual todas as demais imediatamente adjacentes obtivessem densidade do emprego inferior a $D .{ }^{6}$ Seguindo às proposições dos autores, todas as zonas com alta densidade de emprego fariam parte de um subcentro, a não ser que possuíssem uma quantidade de empregos inferior a $E$, ou então fossem isoladas (não fariam parte de um cluster de locais com alta densidade de empregos e emprego total superior a $E$ ). Por fim, o pico do centro seria definido como a zona de maior densidade de empregos ou o grupo de zonas contíguas dentro do subcentro que juntas possuíssem pelo menos $E$ empregos.

Tal como destacam Giuliano \& Small (1991) e McMillen \& Lester (2003), as metodologias de valores de corte têm como mérito, além da simples implementação, a vantagem na comparação intertemporal dos resultados para uma única cidade, visto que o uso de valores de corte fixos para anos diferentes, por exemplo, possibilita uma melhor análise da evolução espacial dos subcentro. Tais procedimentos, contudo, são sensíveis aos valores mínimos de corte, de modo que para diferentes cidades, diferentes valores de corte devem ser aplicados, o que exige conhecimento local do autor, McMillen \& Smith (2003). Destaca-se, também, que as metodologias de valores de corte tendem a identificar um maior número de subcentros se comparadas à AEDE, Baumont et al. (2004).

\subsection{Métodos econométricos}

Os métodos econométricos, em geral, buscam identificar subcentros a partir de resíduos positivos estimados a partir de uma função exponencial de densidade do emprego, ou com uma combinação de métodos não paramétricos e semi-paramétricos, López \& Muñiz (2005). Entre esses métodos, pode-se destacar o trabalho de McDonald (1987) devido ao pioneirismo na elaboração de metodologias formais para a identificação de subcentros. Em breves linhas, McDonald (1987) propõe que os subcentros deveriam produzir clusters de resíduos positivos em uma função simples de densidade de emprego para uma cidade monocêntrica estilizada. Após a inspeção dessa lista de resíduos positivos e estatisticamente significativos, ${ }^{7}$ os subcentros seriam, então, definidos como locais (zonas censitárias) cuja medida de concentração do emprego fosse maior que todas as zonas adjacentes, ${ }^{8}$ tal como se pontua em Giuliano \& Small (1991) e McMillen (2001a).

Os métodos econométricos, além de embutir maior rigor estatístico à análise, são capazes de produzir resultados relevantes, do ponto de vista da identificação de subcentros, mesmo para cidades que o pesquisador não conheça

\footnotetext{
${ }^{6}$ No trabalho de Giuliano e Small, para ser considerada como adjacente, a região teria que possuir uma região de fronteira superior a 0.25 milhas ou 400 metros.

${ }^{7}$ No método de McDonald (1987), a significância estatística comprovaria o efeito do subcentro sobre a estrutura espacial da área urbana em estudo, ou seja, levaria a aumentos locais, por exemplo, do valor da terra e da densidade populacional, tal como o centro principal.

${ }^{8}$ Para essa medida, o autor sugere tanto a densidade do emprego como a razão emprego/população, para o emprego total ou industrial.
} 
bem, McMillen (2001a). Contudo, McMillen \& Lester (2003) destacam que uma das vantagens associadas aos métodos econométricos - que é a adaptabilidade estatística dos valores de corte às condições locais, se torna uma desvantagem quando se analisa a evolução dos subcentros ao longo do tempo. Diferentes valores de corte serão aplicados para diferentes anos, o que afeta as estimativas da função de densidade e a significância estatística. Por esse motivo, McMillen (2001a) destaca que mesmo para os procedimentos mais sofisticados, o conhecimento local é de grande importância para aprimorar os resultados.

\subsection{Análise exploratória de dados espaciais}

A análise exploratória de dados espaciais (AEDE) constitui-se, seguindo a Baumont et al. (2004) e Almeida et al. (2005), de um conjunto de técnicas para a análise estatística de informações geográficas destinadas a descrever padrões de distribuição dos dados em termos da associação espacial, a exemplo da autocorrelação espacial global, autocorrelação espacial local e heterogeneidade espacial. Sobretudo na atualidade, por conta dos avanços na informática, tais técnicas ganharam destaque nos estudos de cunho espacial como um todo, ao se tornarem uma importante ferramenta de análise que possibilita confluir a estatística espacial com as análises, por exemplo, urbanas e regionais, conforme se destaca em Paéz \& Scott (2004).

Entre esses métodos exploratórios, e para a identificação de subcentros, ganhou maior destaque na prática internacional o Indicador Local de Associação Espacial — LISA, proposto em Anselin (1995), técnica pela qual se identificam os subcentros a partir dos padrões de associação espacial do diagrama de dispersão de Moran. Na economia urbana, a elaboração de estudos com base na AEDE é uma prática relativamente recente e que foi impulsionada pela maior disponibilidade de Sistemas de informações geográficas - SIGs e dados georreferenciados. Portanto, ainda é reduzido o número de trabalhos que realizou a identificação de subcentros a partir de técnicas relacionadas à AEDE, como são os casos de Baumont et al. (2004) e Guillain et al. (2003), que analisam, respectivamente, as regiões de Dijon e Ile de France na França.

A AEDE, em grandes linhas, compartilha das mesmas vantagens dos métodos econométricos, ou seja, o rigor estatístico da análise e a possibilidade de obtenção de resultados relevantes mesmo para locais que o autor desconheça. Os SIGs utilizados nesse tipo de procedimento, no entanto, possibilitam uma análise espacial mais dinâmica, seja do ponto de vista da elaboração de mapas, como na construção das matrizes de pesos espaciais. ${ }^{9}$ As técnicas relacionadas à AEDE, contudo, e tal como pontua Almeida et al. (2005), trazem resultados que devem ser avaliados como valiosas dicas acerca do comportamento espacial da variável analisada, o que não dispensa, novamente, o conhecimento local do autor como forma de aprimorar os resultados apontados.

\footnotetext{
${ }^{9} \mathrm{~A}$ matriz de pesos espaciais é uma matriz quadrada $(\mathrm{n} \times \mathrm{n})$ que contém os pesos espaciais de cada unidade sobre outra. Assim, o elemento $w_{i j}$ indica o peso espacial que a unidade $j$ exerce sobre a unidade $i$. Quando a matriz $W$ é construída, independente do critério utilizado (contiguidade, distância etc.), ela é tratada como um fator exógeno.
} 


\subsection{Disseminação internacional e considerações acerca das metodologias para identificação de subcentros}

Como parte final da exposição metodológica, e no intuito de reportar a disseminação dos três procedimentos elencados, além de permitir a comparação de resultados, a Tabela 1 relaciona autores, locais, resultados e o ano do estudo, de artigos voltados à identificação de subcentros.

Com base no conteúdo disposto na Tabela 1 é possível tecer algumas observações gerais sobre os métodos para a identificação de subcentros, em linha com o que observou Kneib (2008). 1) Os procedimentos utilizam basicamente três tipos de variáveis de análise: Densidade do emprego, número de empregos e taxa de emprego por população. 2) O número de subcentros identificados em um mesmo local varia substancialmente, seja por conta do uso de diferentes metodologias, como pelo uso de diferentes valores de corte. 3) Os critérios, sobremaneira nas metodologias de valores de corte, tendem a se flexibilizar para melhor adequação à realidade do local analisado.

Tal como se apresentou no longo desta seção, cada uma das metodologias elencadas é capaz de identificar de forma consistente subcentros em áreas urbanas, independentemente de suas limitações. O entendimento deste trabalho, contudo, é de que o uso conjunto de metodologias possibilita a obtenção de resultados mais acurados. Assim, como contribuições relevantes para este trabalho, destacam-se dois dos estudos apontados na Tabela 1: Baumont et al. (2004), que utiliza a AEDE para identificar subcentros na aglomeração de Dijon, e Coffey \& Shearmur (2001), que testa diversos parâmetros e valores de corte para a identificação de subcentros em Montreal, tal como será detalhado adiante na composição do procedimento metodológico.

\section{O MAUP e a base de dados}

A escolha da base de dados para trabalhos de cunho urbano e regional, no geral, tende a colocar os pesquisadores diante de um trade-off entre o uso de dados bem detalhados (em termos de seções e localizações) e que estão disponíveis, por exemplo, para uma única Região Metropolitana, e dados menos detalhados que são disponibilizados de forma mais ampla, ou seja, que contemplam mais localidades, Coffey \& Shearmur (2001).

O processo de escolha da base de dados, além de delimitar a abrangência espacial do trabalho, é um importante passo da pesquisa para lidar com uma questão central que envolve os trabalhos que utilizam dados geográficos agregados; o problema da unidade de área modificável - MAUP. Na análise urbana, o MAUP surge devido ao fato de que um infinito número de sistemas de zoneamento poder ser construído para subdividir uma cidade em unidades de áreas menores. Dessa forma, os dados reportados para cada unidade de área serão diferentes entre os sistemas de zoneamento, ${ }^{10}$ Paéz \& Scott (2004). A consequência direta da existência de diversos sistemas de zoneamento é que estudos que utilizem uma mesma ferramenta de análise, mas diferentes sistemas de zoneamento de uma mesma cidade, possivelmente, apontem resultados distintos, tal como demonstram Câmara (2002) e Ramos (2002). ${ }^{11}$

\footnotetext{
${ }^{10}$ Para a cidade de São Paulo, por exemplo, é possível a obtenção de dados em pelo menos quatro sistemas de zoneamento diferentes: Distritos, Unidades de Informação Territorializadas (UITS), zonas de origem e destino e setores censitários.

${ }^{11}$ Em Ramos (2002), por exemplo, se avalia as diferenças entre os resultados espaciais da aná-
} 
Tabela 1: Métodos para a identificação de subcentros, locais de aplicação, e resultados

\begin{tabular}{|c|c|c|c|c|}
\hline Metodologia & Estudo & Local e Ano & Critério & Subcentros \\
\hline \multirow{6}{*}{ Valores de corte } & Giuliano \& Small (1991) & Região de Los Angeles, 1980 & $\begin{array}{l}\text { Densidade } \geq 10 \mathrm{emp} / \text { acre Total de } \\
\text { empregos } \geq 10.000\end{array}$ & 32 \\
\hline & Small \& Song (1994) & Região de Los Angeles, 1970 e 1980 & $\begin{array}{l}\text { Densidade } \geq 20 \mathrm{emp} / \text { acre Total de } \\
\text { empregos } \geq 20.000\end{array}$ & $\begin{array}{l}7 \text { em } 1970 \text { e } \\
10 \text { em } 1980\end{array}$ \\
\hline & McDonald \& McMillen (1998) & RM de Chicago, 1980 e 1990 & $\begin{array}{l}\text { Densidade } \geq 10 \mathrm{emp} / \text { acre Total de } \\
\text { empregos } \geq 10.000\end{array}$ & 20 \\
\hline & Coffey \& Shearmur (2001) & $\begin{array}{l}\text { RM de Montreal, } 1996 \text { Total de em- } \\
\text { prego } \geq 7.000\end{array}$ & Razão Emp/resid $\geq 2$ & 6 \\
\hline & Baumont \& Bourdon (2002) & Dijon, 1990 e 1999 & $\begin{array}{l}\text { Densidade } \geq 10 \mathrm{emp} / \text { acre Total de } \\
\text { emprego } \geq 1400\end{array}$ & $\begin{array}{l}6 \text { em } 1990 \text { e } \\
1999\end{array}$ \\
\hline & López \& Muñiz (2005) & RM de Barcelona, 1986 e 1996 & $\begin{array}{l}\text { Densidade: dobro da média Total de } \\
\text { emprego } \geq 1 \%\end{array}$ & $\begin{array}{l}6 \text { em } 1986 \text { e } \\
13 \text { em } 1996\end{array}$ \\
\hline \multirow{4}{*}{ Econometria } & McMillen (2001a) & $\begin{array}{l}\text { Chicago, S. Francisco, Los Angeles, } \\
\text { N. Orleans, Dallas e Houston } 1990\end{array}$ & $\begin{array}{l}\text { a) Resíduos positivos da densidade } \\
\text { do emprego em uma LWR b) Fourier }\end{array}$ & $\begin{array}{l}33 \text { em Chicago, } \\
\text { por exemplo }\end{array}$ \\
\hline & & & $\begin{array}{l}\text { flexível com a distância do subcen- } \\
\text { tro }\end{array}$ & \\
\hline & McMillen $(2001 b)$ & Milwaukee, 2001 & $\begin{array}{l}\text { a) Resíduos positivos da densidade } \\
\text { do emprego em uma LWR b) Fourier } \\
\text { flexível com a distância do subcen- } \\
\text { tros }\end{array}$ & 1 \\
\hline & McMillen \& Smith (2003) & 62 áreas urbanas - EUA, 1990 & $\begin{array}{l}\text { Resíduos positivos da densidade do } \\
\text { emprego em uma LWR Total de em- } \\
\text { prego } \geq 10.000\end{array}$ & $\begin{array}{l}36 \text { em Nova } \\
\text { York, por exem- } \\
\text { plo }\end{array}$ \\
\hline \multirow{3}{*}{ Estatística espacial } & Baumont et al. (2004) & Dijon, 1999 & $\begin{array}{l}\text { I de Moran, Local e Global para den- } \\
\text { sidade do emprego }\end{array}$ & 2 \\
\hline & Guillain et al. (2003) & Ile de France, 1978 e 1997 & $\begin{array}{l}\text { I de Moran, Local e Global para ra- } \\
\text { zão emprego/população }\end{array}$ & $\begin{array}{l}3 \text { em } 1978 \text { e } 7 \\
\text { em } 1997\end{array}$ \\
\hline & Kneib (2008) & Manaus, 2006 & I de Moran local geração de viagens & 15 \\
\hline
\end{tabular}


O MAUP, tal como pontua Wrigley (1996), é composto de dois efeitos, o de escala e o de zoneamento. O efeito de escala é a tendência, dentro de um sistema de unidades de áreas modificáveis, de se obter diferentes resultados estatísticos para um mesmo conjunto de dados quando a informação é agrupada em diferentes níveis de resolução espacial. O efeito de zoneamento, por outro lado, é a variabilidade dos resultados estatísticos obtida dentro de um conjunto de unidades de áreas modificáveis em função das várias possibilidades de agrupamentos em uma dada escala, e não em função da variação do tamanho dessas áreas. (por exemplo, a diferença nos resultados devido à simples alteração das fronteiras ou configurações dentro de uma mesma escala de análise).

É necessário se reconhecer, todavia, que qualquer trabalho que lide com dados agregados por áreas estará sujeito ao MAUP, visto que dados individuais, e que seriam capazes de contornar o problema da agregação espacial, são sigilosos e raramente disponibilizados. Por este motivo, tem-se como prática nos trabalhos regionais e urbanos de cunho espacial a adoção de técnicas e procedimentos capazes de mitigar o impacto que a agregação espacial causa sob os resultados dos estudos. Dentre estas, Câmara (2002) e Paéz \& Scott (2004), por exemplo, destacam o uso de dados agregados em reduzidas dimensões espaciais, tal como setores ou zonas censitárias, ou ainda o uso de critérios de agregação e otimização combinatória.

Nesta pesquisa, no intuito de atenuar os efeitos relacionados ao MAUP, a opção tomada será pelo uso da base de dados da Pesquisa Origem e Destino de 2007 da Região Metropolitana de São Paulo. A opção pelo uso da pesquisa OD, deu-se por conta de dois motivos: da diversidade de informações coletadas e da significativa divisão espacial da base de dados. As pesquisas OD da RMSP, realizadas desde 1967 pela Companhia do Metropolitano de São Paulo — Metrô não se restringem apenas à coleta de dados sobre deslocamento, mas também, entre outros, emprego, matrículas escolares e população. Por esse motivo, além de instrumento base para os estudos e projetos da rede básica do Metrô, tornaram-se um importante instrumento de planejamento urbano. Não obstante a grande quantidade de informações disponibilizadas, os dados da pesquisa OD/RMSP tornam-se atraentes para a pesquisa espacial por conta da divisão geográfica aplicada, posto que a pesquisa de 2007, por exemplo, dividiu a Região Metropolitana de São Paulo em 460 zonas de pesquisa, sendo 320 destas no munícipio de São Paulo.

Os dados da pesquisa de OD/07 da RMSP, por exemplo, foram coletados por meio de questionário aplicado a todos os moradores dos 30.000 domicílios visitados, o que perfez um total de aproximadamente 120 mil entrevistas. A escolha dos domicílios, por sua vez, seguiu ao esquema de amostragem estratificada por faixas de consumo de energia elétrica, sendo que a aplicação de fatores de expansão aos dados da amostra permitiu obter as estimativas de viagens realizadas, empregos e população em cada zona censitária, por exemplo.

lise da população na cidade de São Paulo com 60 anos ou mais para a divisão distrital e de zonas de origem e destino. 


\section{A Região Metropolitana de São Paulo: características e análise da descentralização do emprego no período 1997-2007}

\subsection{Características}

Estabelecida de forma oficial em 1973, a Região Metropolitana de São Paulo, ou Grande São Paulo, é a mais rica e populosa Região Metropolitana Brasileira e um dos maiores aglomerados urbanos do mundo. A expressão da importância e grandeza da RMSP, no âmbito interno e externo, pode ser atestada por alguns de seus números, tal como apresenta a Tabela 2.

Tabela 2: Síntese de características da RMSP

\begin{tabular}{lc}
\hline Características & Valores \\
\hline Área total & $7.943 \mathrm{~km}^{2}$ \\
Municípios & 39 \\
População & 19.956 .590 \\
Número de domicílios & 6.089 .366 \\
Total de empregos & 9.065 .736 \\
PIB & R\$ 613 bilhões \\
\hline Fonte: IBGE (2009, 2010 e 2012) e Pesquisa \\
OD-2007.
\end{tabular}

Embora não possua a maior extensão territorial, ${ }^{12}$ a RMSP destacam-se entre as demais Regiões Metropolitanas Brasileiras devido à grande concentração populacional e de empregos, principalmente os relacionados ao setor de serviços. A grande concentração, tanto populacional, quanto de atividades, se expressa no fato de que a RMSP, cujo território corresponde a 0,93\% da superfície do Brasil, concentre aproximadamente $10 \%$ da população e produza o equivalente a 19\% do PIB nacional (IBGE, 2008). Além da importância no campo da produção de riquezas, a RMSP também exerce papel polarizador sobre as demais metrópoles brasileiras, de maneira que apenas o município de São Paulo, centro da metrópole, serve como sede para $63 \%$ das empresas multinacionais instaladas no Brasil. ${ }^{13}$

Uma análise mais profunda acerca do caráter histórico de formação e consolidação econômica da RMSP, de fato, foge ao escopo deste trabalho, contudo, para a melhor compreensão da área em estudo destacam-se a seguir três das questões que foram de grande valia para a consolidação da RMSP como principal área urbana do país, a saber:

1. A proximidade com o Mar $(70 \mathrm{~km})$ e o traçado dos rios que cortam a RMSP em direção ao interior do Estado, como o Tietê e o Tamanduateí - pois fizeram da RMSP um ponto historicamente estratégico, ao servir, por exemplo, como interligação entre as regiões Sudeste e Centro-Oeste do país.

\footnotetext{
${ }^{12}$ As regiões metropolitanas de Belo Horizonte, ou Porto Alegre, por exemplo, são maiores em extensão.

${ }^{13}$ Prefeitura Municipal de São Paulo.
} 
2. O papel do complexo ferroviário - as ferrovias construídas inicialmente pela necessidade de escoamento da produção cafeeira, a exemplo da São Paulo Railway Company — SPR ${ }^{14}$ fomentaram a concentração de atividades urbanas em seus arredores, como oficinas, armazéns e depósitos. As ferrovias ajudaram, também, a estruturar novas redes de caminhos inter-regionais, fortalecendo a centralidade de São Paulo, palco principal dos negócios do café e onde surgiram as primeiras fábricas e indústrias.

3. As políticas públicas de incentivo à indústria - a partir da década de 1950, políticas de incentivo, como as contidas no Plano de Metas, contribuíram para a instalação massiva de indústrias no espaço que hoje constitui a RMSP, a exemplo dos benefícios oferecidos às empresas que formam o polo automobilístico na região do ABC Paulista.

Bonduki (1998) destaca que as políticas públicas postas em prática na segunda metade do século XX, principalmente, alteraram de maneira direta a dinâmica territorial da metrópole, por meio da mudança na escala das demandas habitacionais necessárias ao assentamento de expressivos contingentes de trabalhadores (migrantes e imigrantes) atraídos pela oferta de empregos na cidade de São Paulo e nos municípios vizinhos. A intensidade do processo migratório é expressa, por exemplo, pelo fato da população na cidade de São Paulo mais que dobrar em um período inferior a 30 anos, passando de 3,5 milhões de habitantes na década de 1950, para 8,6 milhões na década de 1980.

O grande crescimento populacional, aliado à ausência de políticas de planejamento urbano mais incisivas, ${ }^{15}$ permitiu um rápido e desordenado processo de expansão urbana, que fez com que a mancha urbana na RMSP quase triplicasse de tamanho em 40 anos, passando de $874 \mathrm{~km}^{2}$ em 1962 para 2.209 $\mathrm{km}^{2}$ em 2002 (EMPLASA). O rápido crescimento populacional e das áreas urbanizadas distribuiu a população de forma heterogênea e segregada no interior da mancha urbana, (Figura 1 e 2). Tal como pontua Villaça (1998), a população mais rica (menor parcela) concentrou-se, principalmente, nas áreas centrais de municípios mais desenvolvidos e no quadrante sudeste da cidade de São Paulo (Figura 2), enquanto que a população de mais baixa renda (maior parcela) concentrou-se sobremaneira nas regiões periféricas de municípios como São Paulo, Santo André e Guarulhos.

\subsection{Avaliação da descentralização do emprego na RMSP, 1997-2007}

O processo de descentralização dos empregos, via de regra, é o pano de fundo dos trabalhos voltados à identificação de subcentros. Por esse motivo, em grande parcela dos trabalhos, as discussões principais são precedidas de uma investigação, no geral empírica, de aspectos da área urbana avaliada que possam de alguma forma mensurar a descentralização do emprego.

No cenário intra urbano, a descentralização do emprego é tratada em termos da diminuição do papel do centro principal de uma cidade, ou região metropolitana, como principal polo gerador de empregos. Destaca-se assim,

\footnotetext{
${ }^{14}$ Os trilhos da antiga SPR ligavam o porto de Santos à cidade Jundiaí, passando por bairros da capital Paulista como Brás, Barra Funda, Ipiranga e Vila Prudente, além de cidades como Santo André, São Caetano do Sul e Mauá.

${ }^{15}$ O primeiro plano diretor da cidade de São Paulo, por exemplo, data apenas de 1971.
} 


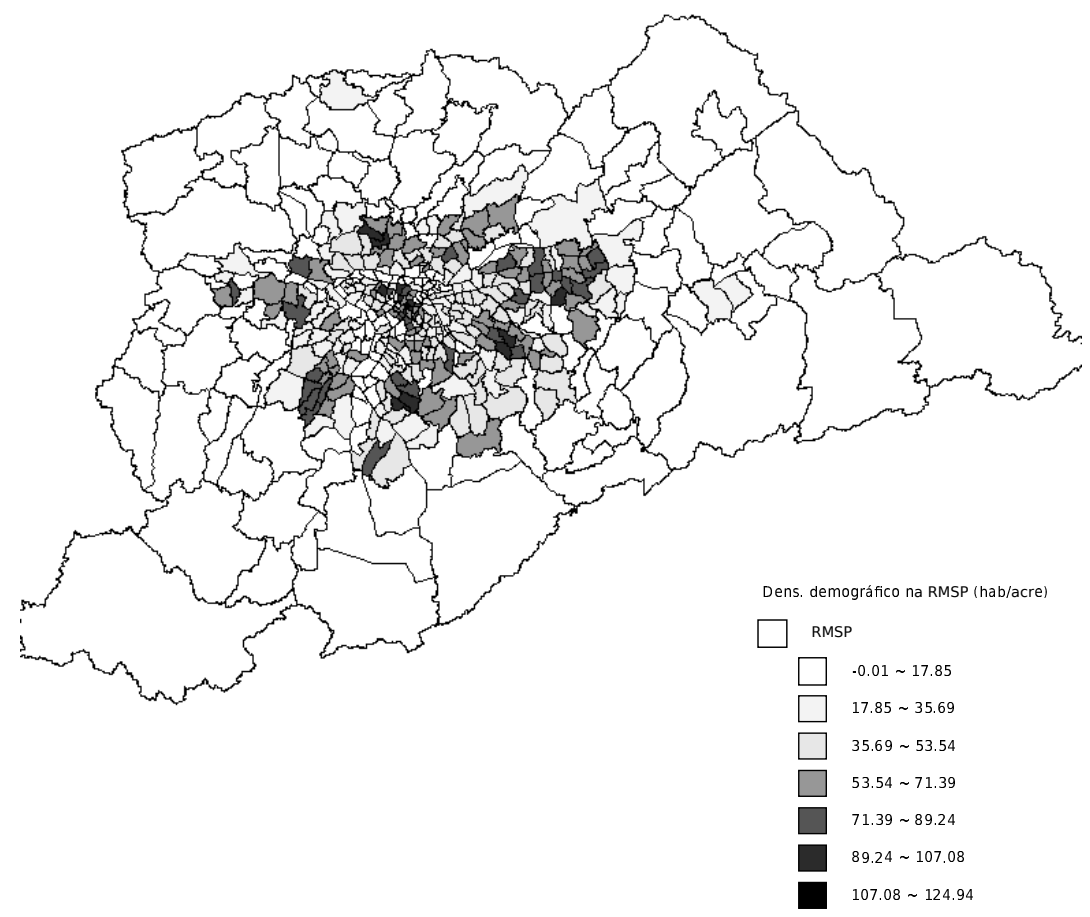

Fonte: Elaboração própria a partir de dados da Pesquisa OD/2007.

Figura 1: Densidade demográfica na RMSP

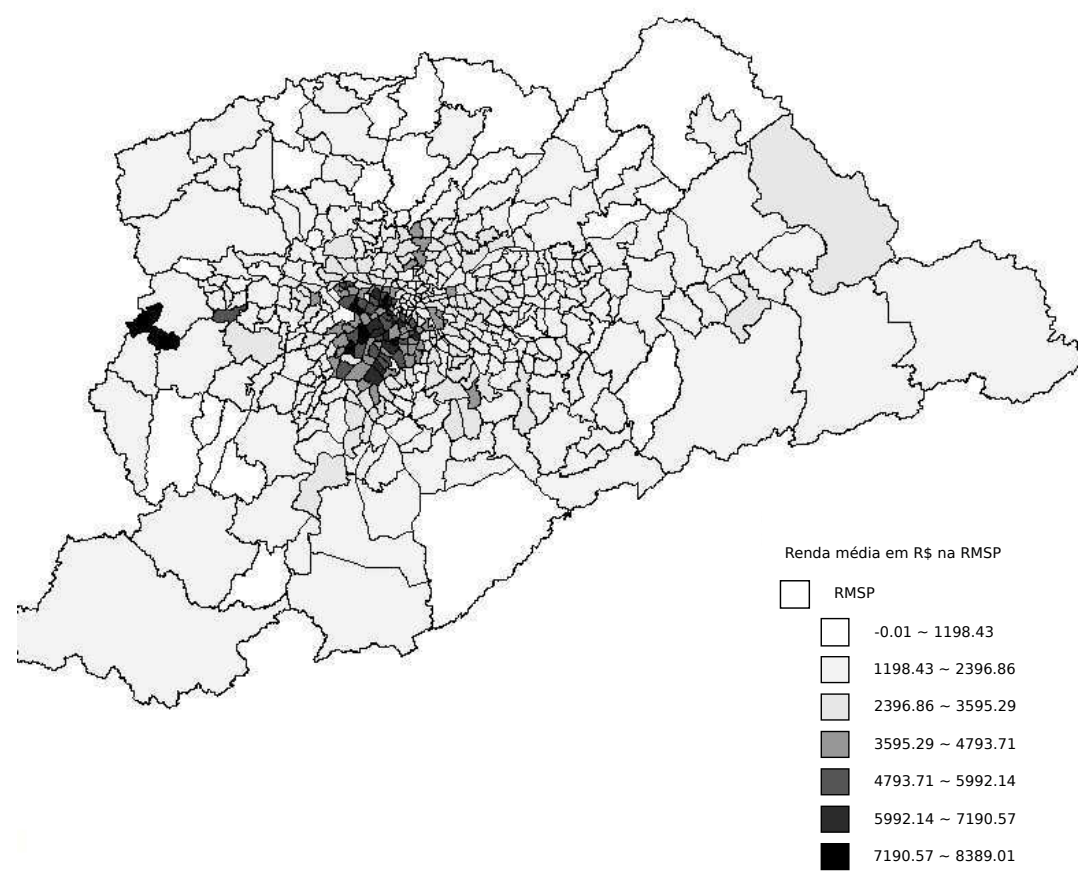

Fonte: Elaboração própria a partir de dados da Pesquisa OD/2007.

Figura 2: Renda per capita na RMSP 
que as análises desta seção procurarão avaliar em que medida o emprego na RMSP se descentralizou entre os anos de 1997 e 2007, tendo como ponto de partida o centro histórico da cidade de São Paulo.

O indicador escolhido para mensurar tal processo, a exemplo do utilizado em López \& Muñiz (2005), será a variação da distância média de cada zona de aferição com respeito ao centro, ponderada pelo percentual de empregos relativo em cada zona, aqui nomeado como indicador DPE, de tal forma que:

$$
D P E=\frac{1}{n} \sum_{i=1}^{n}\left(d_{C B D_{i}} \frac{E_{i}}{E_{R M S P}}\right)
$$

onde $n$ é o número de zonas de aferição, $E_{i}$ é o emprego na zona de aferição $i$, $E_{R M S P}$ o total de empregos na RMSP e $d_{C B D_{i}}$ a distância que separa cada zona de aferição $i$ do centro da RMSP, aqui tido como a zona censitária da Sé, na delimitação da Pesquisa Origem e Destino.

Os resultados obtidos (Tabela 3) apontaram para a descentralização do emprego em todos os ramos de atividade avaliados no período e, consequentemente, no geral. A maior velocidade de descentralização, contudo, observouse no setor industrial (evolução média de $1 \%$ ao ano), enquanto que para o setor de serviços $(0,5 \%$ ao ano) e comércio $(0,65 \%$ ao ano), o ritmo foi menos intenso.

Tal tipo de comportamento, ou seja, maior descentralização dos empregos industriais se comparados ao do setor de serviços, além de enfatizar o caráter de centro de serviços da RMSP, está em sintonia com fatos observados em trabalhos que discutem a descentralização do emprego urbano e os subcentros, a exemplo de Giuliano \& Small (1991) e Glaeser \& Kahn (2001).

Tabela 3: Distância média ao centro ponderada pela concentração relativa dos empregos, $1997-2007$

\begin{tabular}{lccc}
\hline & 1997 & 2007 & Variação \% \\
\hline Geral & 13,76 & 14,35 & $4,29 \%$ \\
Comércio & 13,62 & 14,53 & $6,68 \%$ \\
Indústria & 15,27 & 16,89 & $10,61 \%$ \\
Serviços & 12,92 & 13,53 & $4,72 \%$ \\
\hline \multicolumn{3}{l}{ Dados: Pesquisas OD 1997 e 2007. }
\end{tabular}

Em números absolutos, o processo de descentralização dos empregos na RMSP também pode ser indicado pelo significativo aumento, total e relativo, da quantidade de empregos em bairros mais afastados do centro histórico da cidade de São Paulo e em municípios vizinhos, tal como aponta a Tabela $4 .^{16}$

Embora o maior incremento bruto de empregos tenha ocorrido no 1 circulo, área que corresponde em boa medida as delimitações do centro expandido da cidade de São Paulo, ${ }^{17}$ chama a atenção o aumento da concentração

\footnotetext{
${ }^{16} \mathrm{Na}$ Tabela 4, a evolução da concentração do emprego na RMSP é avaliada a partir de três círculos concêntricos com $9 \mathrm{~km}$ de raio, sendo o mais próximo formado pelas zonas censitárias que o centroide diste até $9 \mathrm{~km}$ da Sé, e o mais afastado formado pelas zonas censitárias em que o centroide diste entre 18 e $27 \mathrm{~km}$ da Sé, ou seja, o limite da parte contínua da mancha urbana.

17 Área da cidade de São Paulo delimitada pelo "mini-anel viário" e na qual vigora o rodízio municipal de veículos.
} 
Tabela 4: Evolução da quantidade e distribuição dos empregos na RMSP, 1997 e 2007

\begin{tabular}{|c|c|c|c|c|c|}
\hline Área & 1997 & $\%$ relativa & 2007 & $\%$ relativa & $\begin{array}{l}\text { Crescimento } \\
\text { do emprego } \\
\text { por circulo }\end{array}$ \\
\hline $\begin{array}{l}1^{\circ} \text { Circulo - até } 9 \mathrm{~km} \\
\text { do centro histórico }\end{array}$ & 2.585 .636 .22 & $37,15 \%$ & 3.287 .279 .97 & $36,26 \%$ & $27,14 \%$ \\
\hline $\begin{array}{l}2^{\circ} \text { Circulo - de } 9,1 \text { a } 18 \\
\mathrm{~km}\end{array}$ & 2.506 .281 .43 & $36,01 \%$ & 2.961 .700 .59 & $32,67 \%$ & $18,17 \%$ \\
\hline $\begin{array}{l}3^{\circ} \text { Circulo - de } 18,1 \text { a } \\
27 \mathrm{~km}\end{array}$ & 1.241 .246 .32 & $17,84 \%$ & 1.865 .074 .47 & $20,57 \%$ & $50,26 \%$ \\
\hline $\begin{array}{l}\text { Demais - acima de } \\
27,1 \mathrm{~km}\end{array}$ & 626.230 .98 & $9,00 \%$ & 951.681 .00 & $10,50 \%$ & $51,97 \%$ \\
\hline Total & 6.959 .394 .95 & $100 \%$ & 9.065 .736 .03 & $100 \%$ & \\
\hline
\end{tabular}

de empregos no 3 circulo, área que engloba regiões de municípios como Guarulhos, Barueri e São Bernardo do Campo. Como se observa, o incremento de 620 mil empregos nessa região ocasionou alta de 50\% na comparação com o período anterior, o que alterou de forma significativa a distribuição dos empregos na RMSP.

Além das análises já realizadas, outra possível forma de se observar as alterações da estrutura espacial do emprego em uma área urbana, como propõe Tsai (2005), é por meio da variação do coeficiente de correlação espacial global (I) de Moran. ${ }^{18} \mathrm{O}$ coeficiente de correlação $I$ de Moran serve para avaliar a autocorrelação espacial de dados espaciais e pode ser apresentado da seguinte forma:

$$
I=\frac{n}{\sum \sum w_{i j}} \frac{\sum \sum w_{i j}\left(y_{i-y}\right)\left(Y_{j-y}\right)}{\sum\left(y_{i}^{-} \bar{y}\right) 2}
$$

onde $n$ é o número de localizações, $y_{i}$ é o valor do atributo em análise e $w_{i j}$ é o peso espacial do par de localizações $i$ e $j$. Assim como um coeficiente de correlação comum, o valor do $I$ de Moran varia entre -1 e 1 , onde -1 indica perfeita dispersão dos dados, zero padrão espacial aleatório e 1 perfeita correlação. Como exemplo de interpretação, nesta pesquisa o coeficiente de correlação 1 indicaria que na RMSP todos os empregos estão concentrados em apenas um único local no espaço.

Os resultados para o I global de Moran em 1997 e 2007, expostos na Tabela 5 , indicam que existe correlação espacial positiva dos empregos na RMSP, ou seja, locais com grande quantidade de empregos tendem a ser próximos (adjacentes), do mesmo modo que locais com pequena quantidade também o são. Contudo, a queda do valor do I de Moran é capaz de denotar mudanças na distribuição espacial dos empregos no período avaliado, no sentido de descentralização esparsa, ou formação de novos clusters de emprego, tal como apontam as simulações de Tsai (2005) e Pereira et al. (2011).

Embora o processo de descentralização do emprego possa ser mais bem avaliado com uma análise temporal superior ao período utilizado, ou seja, 10 anos, todas as análises comparativas conduzidas foram positivas ao indicar

\footnotetext{
${ }^{18}$ Apresentado em 1948, o I de Moran tem a validade estatística dada pelo teste de pseudosignificância, gerado por um processo de permutação.
} 
Tabela 5: I de Moran Global para o emprego na RMSP, 1997-2007

\begin{tabular}{lll}
\hline & 1997 & 2007 \\
\hline$I$ de Moran & 0,36 & 0,29 \\
\hline Dados: Pesquisas OD 1997 e \\
2007, cálculos realizados no \\
software livre Geoda.
\end{tabular}

a crescente concentração de empregos em regiões mais distantes do centro da RMSP, fato que dá sustentação e justifica a identificação de subcentros de emprego, tanto quanto as demais avaliações que podem ser realizadas.

\section{Componentes da proposta metodológica para a Identificação de subcentros}

Tal como já se apontou, este trabalho pretende propor um procedimento de dois estágios para a identificação de subcentros, englobando duas das metodologias apresentadas na seção três, a saber: a AEDE, no intermédio do LISA proposto em Anselin (1995), e o estabelecimento de valores de corte, seguindo aos parâmetros indicados no trabalho de Coffey \& Shearmur (2001).

O uso conjunto dessas duas ferramentas vislumbra confluir aspectos positivos e suplantar pontos sensíveis relacionados a cada um dos procedimentos. Dessa forma, por exemplo, tem-se que no primeiro estágio, por meio da AEDE, será possível a obtenção de resultados com significância estatística e que independem do conhecimento local do autor. Já no segundo estágio, por meio da imposição de valores corte, será possível, além de corrigir distorções relacionadas a análises estatísticas espaciais, qualificar melhor os sub-centros por meio da imposição de um critério de análise adicional.

Assim, a diretriz do procedimento proposto será: 1) No intermédio da AEDE, identificar um grupo de localizações iniciais interpretando-as como potenciais subcentros; 2) Na imposição de valores de corte, buscar a melhor especificação dos subcentros e identifica-los na forma final.

\subsection{Especificação do procedimento do primeiro estágio}

O método que será utilizado no primeiro estágio, a estatística I local de Moran, seguindo a Anselin (1995) e Almeida et al. (2005) tem duas funções básicas: 1) Identificar locais que são clusters espaciais significativos; 2) Servir como diagnóstico para a instabilidade local nas medidas de associação espacial global, a exemplo do apontamento de "outliers". ${ }^{19}$

O coeficiente $I$ local de Moran para uma variável $y$ padronizada, observada na região $i, z_{i}$, pode ser expresso como:

$$
i=z_{i} \sum_{j} w_{i j} z_{j}
$$

$I$

\footnotetext{
${ }^{19} \mathrm{Na}$ AEDE, um outlier espacial, por exemplo, pode se tratar de um local no qual o comportamento da variável analisada destoe em grande medida dos demais.
} 
onde as observações $z_{i}, z_{j}$ estão calculadas na forma de desvio da média, e o somatório $j$ computa apenas valores vizinhos $i \in J_{i}$ ( $j_{i}$ é o conjunto de vizinhos de $i$ ).

Tal como pondera Anselin (1995), a vantagem da estatística local de Moran sobre outros LISAs, como a estatística local $G_{i}(d)$ de Getis \& ORD (1992), é que esta medida possibilita a decomposição dos padrões de associação espacial em quatro categorias, que se originam a partir da comparação da distribuição espacial da variável com a média local da vizinhança ponderada pela matriz de pesos espaciais. Os padrões de associação espacial indicados pela versão local do $I$ de Moran dizem respeito aos quatro quadrantes do diagrama de dispersão de Moran, ${ }^{20}$ da seguinte forma:

- Associação espacial positiva; quadrante AA (alto-alto), valores positivos, médias positivas; quadrante BB (baixo-baixo), valores negativos, médias negativas.

- Associação espacial negativa: quadrante AB (alto-baixo), valores positivos, médias negativas; quadrante BA (baixo-alto) valores negativos, médias positivas.

Assim sendo, e tal como conduzido nos trabalhos de Baumont et al. (2004) e Guillain et al. (2003), com base no total de empregos, o primeiro estágio do procedimento identificará como potenciais subcentros as zonas censitárias classificadas no regime de associação espacial positiva AA (Alto-Alto), ou seja, locais e regiões que tendem a formar concentrações de emprego significativa no contexto espacial.

\subsection{Especificação do procedimento do segundo estágio}

O procedimento de valores de corte, ferramenta deste estágio, tal como já se pontuou, terá o intuito de aprimorar os resultados finais, tornando-os mais robustos em termos de localização, relevância e extensão. Para tanto, e como prática já consolidada na literatura, se fez a opção pelo uso de dois parâmetros de corte, o total de empregos e a razão E/PO, tal como especificado em Coffey \& Shearmur (2001).

Tal como será aplicado, o primeiro parâmetro de corte - total de empregos - visará, principalmente, mitigar erros do processo de análise exploratória espacial por meio da imposição de uma quantidade mínima de empregos para que uma zona censitária seja qualificada como subcentro, ou parte integrante de um. Este corte pretende evitar, por exemplo, que locais com pequena quantidade de emprego apontados no primeiro estágio, sejam qualificados como subcentros. O valor escolhido para perfazer o corte, após uma série de testes, ${ }^{21}$ foi a quantidade mínima de 31.500 empregos, valor que equivale ao dobro da mediana dos empregos na RMSP

$\mathrm{O}$ segundo parâmetro para corte, medida que chamaremos de razão E/PO, se refere à relação entre o número de pessoas que trabalham em determinada

\footnotetext{
${ }^{20}$ Vide Figura A.1.

${ }^{21}$ Os valores de 10.000 e 20.000 para o total de empregos, amplamente utilizados na literatura, apontaram resultados não satisfatórios para a identificação de subcentros na RMSP. A grande concentração de empregos que existe na RMSP, aliado a problemas relacionados ao MAUP, fizeram desses valores limites baixos para a caracterização de um local como subcentro metropolitano relevante.
} 
zona censitária (o total de Empregos, E) e a população ocupada e que reside nesta mesma zona censitária (PO), calculada da seguinte forma:

$$
E / P O=\frac{E}{P O}
$$

Tal medida foi proposta inicialmente no trabalho de Forstall \& Greene (1997), como forma de refinar a razão E/P, ou seja, a relação entre os totais de empregos (E) e população $(\mathrm{P})$ em cada zona censitária, medida utilizada, por exemplo, no trabalho de McDonald (1987). De forma funcional, o valor de 1,2 para a razão E/PO, indica que determinado local possui $20 \%$ mais empregos do que população ocupada, ao passo que um valor de 0,5 indicaria que a unidade espacial possui o montante total de empregos equivalente à metade da população ocupada. Tal como se argumenta em Forstall \& Greene (1997), a razão E/PO possui a vantagem de padronizar a distribuição dos empregos na base da distribuição residencial dos trabalhadores, em contraste à densidade do emprego, que faz a padronização com base na área. Os mesmos autores pontuam, ainda, que o cálculo da razão E/PO, na ausência de matrizes de Origem e Destino, pode servir como estimativa dos movimentos pendulares, uma vez que pondera o nível de equilíbrio entre a população ocupada e o emprego em cada zona censitária.

Além da vantagem atrelada a não padronização com base na área, o uso da razão E/PO como segundo parâmetro para corte, neste trabalho, visará dar ênfase ao caráter econômico usualmente relacionado aos subcentros. Assim sendo, e para atender tais fins, o valor de corte para a razão E/PO, tal como utilizado em Coffey \& Shearmur (2001), será 2, o que indicará, portanto, que um subcentro deverá possuir pelo menos duas vezes mais empregos do que população ocupada. ${ }^{22}$

Dessa forma, ao final da especificação dos valores de corte, tem-se que um subcentro, além de previamente qualificado sob o padrão Alto-Alto na estatística local de Moran, deverá possuir pelo menos 31.500 empregos e possuir uma razão E/PO superior a 2.

\section{Resultados e Análises}

Como resultado do primeiro estágio do procedimento, a Figura 3 apresenta os resultados espaciais da estatística local de Moran (Lisa Cluster Map), calculada a partir do total de empregos em cada zona censitária. ${ }^{23}$

A disposição dos clusters de emprego apontados na Figura 3 sugere a existência de pelo menos sete subcentros na RMSP, ${ }^{24}$ nomeados e numerados da seguinte forma:

1) Centro histórico da cidade de São Paulo;

2) Eixo Paulista - Faria Lima (São Paulo);

\footnotetext{
${ }^{22} \mathrm{~A}$ razão E/PO, tal como será calculada neste trabalho, não engloba informações a respeito da quantidade de trabalhadores que residem e trabalham na mesma zona censitária.

${ }^{23}$ Para a obtenção dos resultados assumiu-se uma matriz de pesos espaciais sob a convenção queen de primeira ordem e o nível de significância adotado foi o de 0,05, após 9999 permutações. Todos os cálculos e as figuras foram obtidos por meio do software livre Geoda.

${ }^{24} \mathrm{O}$ nome e o município a que pertencem todas as zonas apontadas pelo regime de associação espacial Alto-Alto (cor vermelha) estão na Tabela A.2 deste artigo.
} 


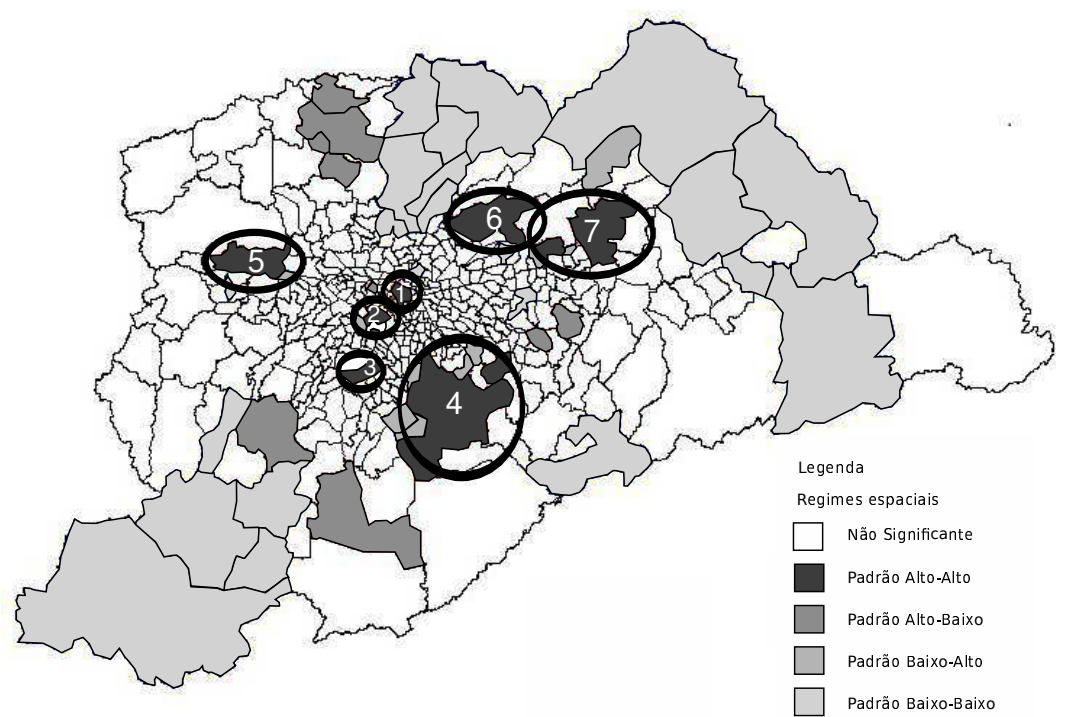

Fonte: Elaboração própria a partir de dados da Pesquisa OD/2007.

Figura 3: Mapa de clusters - estatística local de Moran

3) Santo Amaro (São Paulo);

4) São Bernardo do Campo (em uma região que abrange também porções dos municípios de Santo André, São Caetano do Sul e Diadema, região conhecida como ABCD);

5) Barueri (Alphaville);

6) Guarulhos;

7) Itaquaquecetuba/São Miguel Paulista (região que une Itaquaquecetuba ao bairro da zona leste da cidade de São Paulo).

Na sequência, e seguindo aos procedimentos do segundo estágio, as 42 zonas censitárias que formam os sete subcentros apontados no mapa 3 foram submetidas aos valores de corte propostos, ou seja, total de empregos $\geq 31.500$ e razão $\mathrm{E} / \mathrm{PO} \geq 2$. Nessa etapa, das 42 zonas censitárias apontadas, 26 foram descartadas por não atenderem aos critérios estabelecidos no segundo estágio, sendo que dessas: 10 não atenderem apenas ao critério mínimo de empregos, outras 10 não atenderam apenas ao critério mínimo para a razão E/PO e 6 não atenderam ambos os requisitos.

Assim, como visualização espacial dos resultados finais, a Figura 4 aponta a localização das 16 zonas censitárias que atenderam a todos os requisitos do procedimento metodológico proposto ${ }^{25}$ e que formam, então, seis subcentros na RMSP.

Ao se comparar os resultados finais com os resultados obtidos após a aplicação do LISA de Moran (Figura 3), é possível observar que o segundo estágio do procedimento (valores de corte), eliminou por inteiro o subcentro situado

\footnotetext{
${ }^{25}$ As zonas censitárias que compõem de forma final cada um dos subcentros podem ser consultadas na Tabela A.1 deste trabalho.
} 


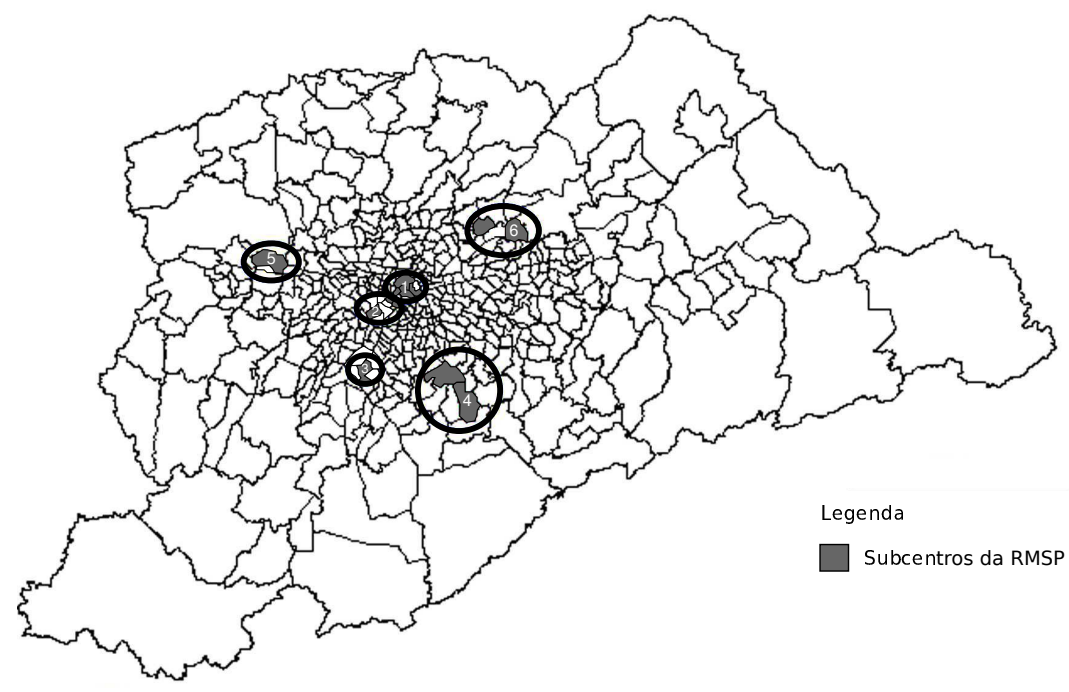

Fonte: Elaboração própria a partir de dados da Pesquisa OD/2007.

Figura 4: Subcentros identificados na RMSP

na região de Itaquaquecetuba que faz divisa com o bairro de São Miguel Paulista (7), além de parte significativa das zonas que compunham os subcentros localizados no ABCD (4), Guarulhos (6) e Barueri (5).

Do ponto de vista da localização, os resultados alcançados (Figura 4) se alinharam com o observado em trabalhos dessa mesma tipologia, de modo que todos os subcentros, por exemplo, se encontram próximos a entroncamentos das redes de trens urbanos, do metrô, ou de importantes rodovias e avenidas, a exemplo do que observam McDonald \& McMillen (1998). A localização dos subcentros, em grande medida, também se alinha com a considerada em trabalhos de outras vertentes e que abrangem a RMSP, a exemplo de Vieira \& Haddad (2012) e Gomes et al. (2012).

Embora a localização dos subcentros seja condizente e a relevância destes no contexto metropolitano aparentemente não questionável, a real área ocupada pelos subcentros pareceu subestimada. Tal observação deve-se ao fato de zonas censitárias com grande concentração de empregos e elevada razão E/PO, como são os casos da Chácara Itaim e Pinheiros na região do subcentro da Paulista-Faria Lima, da Granja Julieta na região do subcentro de Santo Amaro, e de Santo André no subcentro do ABCD, não terem sido identificadas como componentes dos respectivos subcentros. Tal tipo de subestimação pode ser atribuída a dois fatores não totalmente controlados: 1) Às quebras impostas no zoneamento utilizado - um típico problema relacionado aos MAUPs e, tão logo, aos trabalhos de cunho espacial, tal como se destacou na seção 4. 2) Ao procedimento de análise do primeiro estágio, uma vez que a análise utilizada leva em conta o valor médio da variável na vizinhança, ou seja, caso o comportamento da média da variável na vizinhança não seja simétrico, por exemplo, o LISA de Moran tende a caracterizar tal localidade como não signi- 


\section{ficativa no Mapa de Clusters (Figura 3). ${ }^{26}$}

Assim sendo, pode-se inferir que os resultados alcançados pelo procedimento proposto teriam como tendência apontar para o "centro dos subcentros", local que não necessariamente é o pico local de empregos e da razão E/PO. Essa característica do método sugere, então, a necessidade de análises adicionais, caso o estudo, para o alcance de outros objetivos, necessite, por exemplo, de uma melhor especificação sobre a extensão dos subcentros.

\subsection{Análise secundária: Especialização do emprego nos subcentros}

No leque de possíveis análises que se abre a partir da identificação de subcentros, este trabalho propõe como análise complementar e demonstrativa o cálculo do Quociente Locacional - QL. ${ }^{27}$ Tal como pontua Suzigan (2003), e adaptando para a análise proposta, o quociente locacional será a razão entre a participação de uma determinada classe de empregos no total de empregos de uma zona censitária e a participação dessa mesma classe de empregos no total global da RMSP, ou seja:

$$
Q L_{i}^{R}=\left[\frac{\frac{E_{i}^{R}}{E^{R}}}{\frac{E_{i}^{N}}{E^{N}}}\right]
$$

onde $E_{i}^{R}$ e $E^{R}$ denotam, respectivamente, o total de empregos no setor $i$ e o total de empregos na zona censitária $R, E_{i}^{N}$ e $E^{N}$ denotam o total de empregos no setor $i$ e o total de empregos na RMSP. Expresso dessa forma, quanto maior o QL maior será a especialização da zona censitária no setor respectivo, de forma que valores superiores a $1(>1)$ indicam especialização local. ${ }^{28}$

Tal como já se destacou, na RMSP, como um todo predominam as atividades voltadas ao setor de serviços, ao concentrar mais de $60 \%$ do total dos empregos. Entretanto, ainda há expressiva presença de indústrias em certas regiões da RMSP. Por esse motivo, primeiramente foi feito o cálculo do QL para o setor de serviços e indústria em todos os subcentros, sendo que nos subcentros em que os níveis de especialização forem maiores no setor de serviços, será feito um novo cálculo do QL, dessa vez, contudo, avaliando a especialização no setor de serviços a partir das oito categorias disponibilizadas na pesquisa OD/2007. ${ }^{29}$ Nesta seção, cabe o destaque, de que será feita a análise

\footnotetext{
${ }^{26}$ Tal situação se observa, por exemplo, no caso da Granja Julieta na região de Santo Amaro, que faz divisa com a zona censitária de Paraisópolis, esta última composta em grande medida por favelas.

${ }^{27} \mathrm{O}$ QL, medida de amplo uso em análises regionais, é utilizado de modo geral para indicar a especialização relativa de uma indústria em uma determinada região, contudo, nesta etapa da análise se propõe a redução da amplitude do QL para o nível intra urbano, avaliando, então, o nível de especialização nos subcentros.

${ }^{28} \mathrm{Na}$ ausência de variáveis de controle, o QL deve ser avaliado com ressalvas, pois elevados índices podem remeter a uma baixa estrutura de empregos local, o que leva a uma superestimação do índice em virtude, por exemplo, da presença local de uma grande empresa, Suzigan (2003). Note que nesse sentido, contudo, o total mínimo de empregos, procedimento do segundo estágio, já serviu como variável de controle para o QL.

${ }^{29} \mathrm{O}$ ideal para esse tipo específico de análise são os dados da RAIS, através das classes de serviços do CNAE - Classificação Nacional da Atividade Econômica. Entretanto, os dados da RAIS 2006 e da pesquisa OD/2007 divergem em relevante medida, seja na disponibilidade espacial, como pelo fato da RAIS não computar os empregos informais e do setor público. Para os empregos da indústria a pesquisa OD/2007 não faz nenhuma distinção.
} 
com base no agrupamento dos dados das zonas censitárias que compõem cada subcentro, tal como dispõe a Tabela A.1.

Tabela 6: QL — Indústria e Serviços nos subcentros

\begin{tabular}{lcc}
\hline Subcentro & QL Indústria & QL Serviços \\
\hline Centro histórico de SP (1) & 0,24 & 1,16 \\
Paulista-Faria Lima (2) & 0,24 & 1,30 \\
Santo Amaro (3) & 0,67 & 1,05 \\
ABCD (4) & 1,66 & 0,87 \\
Barueri (5) & 1,05 & 1,04 \\
Guarulhos (6) & 2,53 & 0,77 \\
\hline Fonte: Elaboração própria a partir de dados da pesquisa OD/07.
\end{tabular}

Fonte: Elaboração própria a partir de dados da pesquisa OD/07.

Os dados da Tabela 6 apontam para a maior especialização em atividades industriais nos subcentros localizados em Guarulhos e no ABCD, enquanto que no setor de serviços a maior especialização deu-se nos subcentros localizados na cidade de São Paulo. Assim sendo, os dois primeiros serão omitidos da análise de especialização dos serviços.

Tabela 7: QL por tipo de serviço nos subcentros especializados

\begin{tabular}{lcccc}
\hline Tipo de serviço & $\begin{array}{l}\text { Centro Histó- } \\
\text { rico SP (1) }\end{array}$ & $\begin{array}{l}\text { Paulista-Faria } \\
\text { Lima (2) }\end{array}$ & $\begin{array}{l}\text { Santo } \\
\text { Amaro (3) }\end{array}$ & Barueri (5) \\
\hline Creditício - Financeiro & 3,24 & 3,24 & 0,37 & 1,38 \\
Pessoais & 0,23 & 0,28 & 0,73 & 0,32 \\
Alimentação & 0,63 & 0,52 & 1,07 & 0,92 \\
Saúde & 0,66 & 1,26 & 1,41 & 1,05 \\
Educação & 0,42 & 0,42 & 1,43 & 0,08 \\
Especializados & 1,98 & 1,36 & 0,67 & 1,63 \\
Adm. Pública & 1,94 & 0,42 & 1,92 & 0,08 \\
Transporte/logística & 0,33 & 0,42 & 0,56 & 2,09 \\
\hline
\end{tabular}

Fonte: Elaboração própria a partir de dados da Pesquisa OD/2007

A análise dos dados apresentados nas Tabelas 6 e 7, no caráter demonstrativo desta etapa, apontam que: 1) Dos subcentros identificados, Guarulhos e $A B C D$ constituem subcentros com maior especialização relativa no setor da indústria, as zonas censitárias que formaram o subcentro do $\mathrm{ABCD}$, por exemplo, concentram mais de 50.000 postos de trabalho na indústria. 2) Os subcentros especializados em serviços, ou seja, Centro histórico, Paulista-Faria Lima, Santo Amaro e Barueri, diferem relativamente quanto à especialização no tipo de serviços. Assim, pode-se observar, por exemplo, o QL elevado para o setor de serviços creditício-financeiros e especializados no centro histórico e na Paulista-Faria Lima, e dos serviços relacionados ao setor de logística em Barueri, município que além de oferecer incentivos fiscais às empresas desse setor, localiza-se em ponto estratégico, às margens de importantes rodovias que rumam ao interior do Estado e do Rodoanel.

Como ilustração final, a Figura 5 apresenta novamente os seis subcentros identificados pelo procedimento metodológico proposto e aponta, ainda, a atividade com maior QL (especialização) em cada um. 


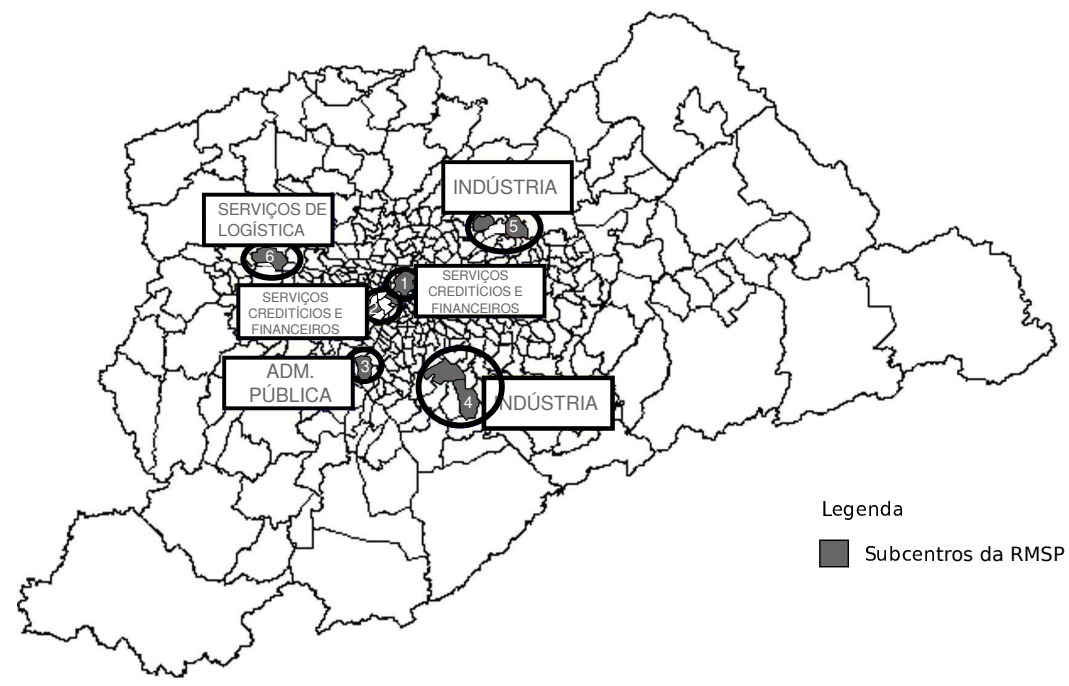

Fonte: Elaboração própria a partir de dados da Pesquisa OD/2007.

Figura 5: Subcentros e especialização

\section{Conclusão}

O procedimento metodológico proposto neste trabalho visou à obtenção de resultados robustos acerca da relevância, extensão e localização de subcentros, tendo como pano de fundo de testes a RMSP. Para tanto, se propôs um procedimento de dois estágios e que uniu dois distintos procedimentos para a identificação de subcentros utilizados na prática internacional, a AEDE e o método de valores de corte, visando confluir aspectos positivos e suplantar pontos sensíveis relacionados a cada um destes procedimentos.

A principal vantagem do procedimento mostrou-se na obtenção de resultados que obedecem a critérios estatísticos, devido ao uso da AEDE, e prezam pela melhor especificação dos subcentros por meio das variáveis de controle do método de valores de corte. As análises paralelas conduzidas ao longo do trabalho também se mostraram valiosas, seja como justificativa ao estudo, no caso da descentralização do emprego no período 1997-2007, como comprobatórias de sua relevância, no caso da análise secundária da especialização das atividades nos subcentros.

Dessa forma, é possível inferir que os locais identificados como subcentros na RMSP constituem de fato importantes centralidades no cenário metropolitano, condizentes, inclusive, com o esperado e apontado por outros trabalhos. Contudo, devido a problemas que podem ser atribuídos ao MAUP e que não foram plenamente contornados, assim como limitações intrínsecas aos procedimentos metodológicos utilizados, a real área ocupada pelos subcentros apontados pareceu subestimada, de modo que os resultados alcançados tenderiam a apontar mais diretamente para o "centro dos subcentros".

Por fim, destaca-se que a identificação de subcentros urbanos nas Regiões Metropolitanas Brasileiras constitui uma importante e vasta área de estudos 
urbano-econômicos, vis-à-vis sua relevância ao possibilitar a avaliação e compreensão mais acurada das dinâmicas do meio urbano.

\section{Referências Bibliográficas}

Almeida, E. S., Haddad, E. A. \& Hewings, G. J. D. (2005), 'The spatial patterns of crime in minas gerais: An exploratory analysis', Economia Aplicada 9(1).

Anas, A., Arnott, R. \& Small, K. A. (1998), 'Urban spatial structure', Journal of Economic Literature 36, 1426-1464.

Anselin, L. (1995), 'Local indicators of spatial association - lisa', Geographical Analysis 27(2), 93-115.

Baumont, C. \& Bourdon, F. (2002), Centres secondaires et recomposition économique des espaces urbain, le casda communauté de l'aglomération dijonnaise (1990; 1999), LATEC Working Paper 4, Universidade de Bourgogne, Dijon.

Baumont, C., Ertur, C. \& Gallo, J. L. (2004), 'Spatial analysis of employment and population density: The case of the agglomeration of dijon, 1999', Geographical Analysis 36(2).

Bonduki, N. G. (1998), Origens da habitação social no Brasil. Arquitetura Moderna, Lei do Inquilinato e difusão da casa própria, Estação Liberdade: FAPESP.

Castells, M. (1983), A Questão Urbana, Paez e Terra.

Coffey, W. J. \& Shearmur, R. G. (2001), 'The identification of employment centres in canadian metropolitan areas: the example of montreal, 1996', The Canadian Geographer 45(3), 371-386.

Câmara, G. (2002), Análise espacial de áreas, mimeo.

Forstall, R. L. \& Greene, R. P. (1997), 'Defining job concentrations: the los angeles case', Urban Geography 18, 705-739.

Fujita, M. \& Ogawa, H. (1982), 'Multiple equilibria and structural transition of nonmonocentric urban configurations', Regional Science and Urban Economics 12.

Getis, A. \& ORD, J. K. (1992), 'The analysis of spatial association by use of distance statistics', Geographical Analysis 24, 189-206.

Giuliano, G. \& Small, K. A. (1991), 'Subcenters in the los angeles region', Regional Science and Urban Economics 21, 163-182.

Glaeser, E. L. \& Kahn, M. E. (2001), Decentralized employment and the transformation of the american city, Working Paper 8117, NBER.

Gomes, E. G., Maciel, V. F. \& Kuwahara, M. Y. (2012), Determinantes dos preços de imóveis residenciais no município de são paulo, in ' $40^{\circ}$ Encontro Nacional de Economia da ANPEC, Porto de Galinhas, PE'. 
Greene, D, L. (1980), 'Recent trends in urban spatial structure', Growth and Change 11(2), 29-40.

Guillain, R., Gallo, J. L. \& Boiteux-Orain, C. (2003), The evolution of the spatial and sectoral patterns in ile-de-france over 1978-1997, in '50th North American Meetings of the Regional Science Association International (RSAI)'.

Jacobs, J. (1969), The Economy of cities, New York: Vintage.

Kneib, E. C. (2008), Subcentros Urbanos: Contribuição Conceitual e Metodológica à sua definição e identificação para planejamento de Transportes, Doutorado em transportes, Faculdade de Técnologia, Universidade de Brasília.

López, M. A. G. \& Muñiz, I. (2005), 'Employment descentralisation: polycentric compaction or sprawl? the case of the barcelona metropolitan region 1986-1996', Document de Treball, Facultat de Ciències Econòmiques i Empresarials, Universitat Autònoma de Barcelona.

Marshall, A. (1982), Princípios de Economia: tratado introdutório, Vol. 2, Abril Cultural.

McDonald, J. F. (1987), 'The identification of urban employment subcenters', Journal of Urban Economics 21, 242-258.

McDonald, J. F. \& McMillen, D. P. (1998), 'Suburban subcenters and employment density in metropolitan chicago', Journal of Urban Economics 43(3), 157180 .

McMillen, D. P. (2001a), 'Nonparametric employment subcenter identification', Journal of Urban Economics 50, 448-473.

McMillen, D. P. (2001b), 'Polycentric urban structure: The case of milwaukee', Economic Perspectives 25(2), 15-27.

McMillen, D. P. \& Lester, T. W. (2003), 'Evolving subcenters: employment and population densities in chicago, 1970-2020', Journal of Housing Economics $12,60-81$.

McMillen, D. P. \& Smith, S. C. (2003), 'The number of subcenters in large urban áreas', Journal of Urban Economics 53(3), 321-338.

Paéz, A. \& Scott, D. M. (2004), 'Spatial statistics for urban analysis: A review of techniques with examples', GeoJournal 61, 53-67.

Pereira, R. M. P., Nadalin, V., Monasterio, L. \& Albuquerque, P. H. M. (2011), Quantificando a centralidade urbana: uma proposta de índice simples e comparação internacional, Texto para discussão 1675, IPEA.

Ramos, F. R. (2002), Análise espacial de estrutura intra-urbanas: o caso de são paulo, Mestrado em sensoriamento remoto, Instituto Nacional de Pesquisas Espaciais (INPE), São José dos Campos. 
Richardson, H. W. (1997), Monocentric vs. policentric models: The future of urban economics in regional science, in 'Presidential Address to the Western Regional Science Association', Vol. 27, University of Southern Califórnia, Califórnia.

Siqueira, L. P. R. (2012), Identificação de subcentros na cidade de são paulo: uma abordagem ligada à nova economia urbana, Mestrado em economia política), Pontíficia Universidade Católica de São Paulo.

Small, K. A. \& Song, S. (1994), 'Population and employment densities: Structure and change', Journal of Urban Economics 36, 292-313.

Suzigan, W. (2003), 'Coeficientes de gini locacionais — gl: aplicação à indústria de calçados do estado de são paulo', Nova Economia 13(2), 39-60.

Tsai, Y. H. (2005), 'Quantifying urban form: compactness versus "sprawl"', Urban Studies 42(1), 141-161.

Vieira, R. S. \& Haddad, E. A. (2012), Índice de acessibilidade para são paulo, in ' $40^{\circ}$ Encontro Nacional de Economia da ANPEC, Porto de Galinhas, PE'.

Villaça, F. (1998), Espaço intra-urbano no Brasil, Studio Nobel.

White, M. J. (1999), 'Urban areas with decentralized employment: Theory and empirical work', Handbook of Regional and Urban Economics 3, 13751412.

Wrigley, N. (1996), Analysing, modelling, and resolving the ecological fallacy, in P. Longley \& M. Batty, eds, 'Spatial Analysis: Modelling in a GIS Environment', New York, John Wiley e Sons, pp. 25-41.

\section{Apêndice A}

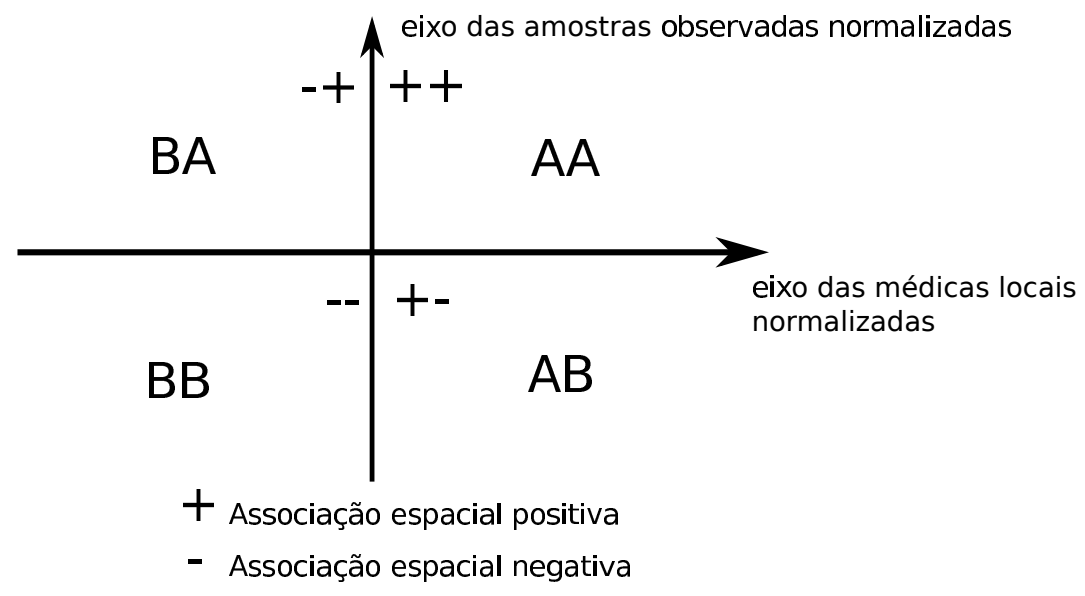

Figura A.1: Diagrama de dispersão de Moran 
Tabela A.1: Zonas censitárias que compõe os subcentros identificados

\begin{tabular}{|c|c|c|c|c|c|c|}
\hline Subcentro & Centro Hist. São Paulo & $\begin{array}{l}\text { Paulista - Faria } \\
\text { Lima }\end{array}$ & Santo Amaro & $\mathrm{ABCD}$ & Guarulhos & Barueri \\
\hline $\begin{array}{l}\text { Zonas } \\
\text { censitárias } \\
\text { componentes }\end{array}$ & $\begin{array}{l}\text { Sé } \\
\text { Parque Dom Pedro } \\
\text { Vila Buarque } \\
\text { Santa Cecília } \\
\text { Ladeira da Memória } \\
\text { Santa Efigênia } \\
\text { República }\end{array}$ & $\begin{array}{l}\text { Campinas } \\
\text { Trianon } \\
\text { Jd. Europa }\end{array}$ & Santo Amaro & $\begin{array}{l}\text { Rudge Ramos } \\
\text { SBC }\end{array}$ & $\begin{array}{l}\text { Guarulhos } \\
\text { Cumbica }\end{array}$ & Tamboré \\
\hline
\end{tabular}


Tabela A.2: Zonas censitárias apontadas no regime de associação espacial Alto-Alto

\begin{tabular}{|c|c|c|c|}
\hline Nome & $\begin{array}{l}\text { Município } \\
\text { pertencente }\end{array}$ & Nome & Município pertencente \\
\hline Sé & São Paulo & Jardim Helena & São Paulo \\
\hline Pq. Dom Pedro & São Paulo & Anchieta & São Paulo \\
\hline João Mendes & São Paulo & Guarulhos & Guarulhos \\
\hline Ladeira da Memória & São Paulo & Cumbica & Guarulhos \\
\hline República & São Paulo & Jd. America & Guarulhos \\
\hline Santa Efigênia & São Paulo & Aeroporto & Guarulhos \\
\hline São C. Pinhal & São Paulo & Itaquaquecetuba & Itaquaquecetuba \\
\hline Vila Buarque & São Paulo & Bonsucesso & Itaquaquecetuba \\
\hline Sta Cecília & São Paulo & Valparaíso & Santo André \\
\hline Vila Olímpia & São Paulo & Pq. Das Nações & Santo André \\
\hline Hélio Pelegrino & São Paulo & Jd. Do Estádio & Santo André \\
\hline Vila Cordeiro & São Paulo & Planalto & São Bernardo do Campo \\
\hline Campinas & São Paulo & Rudge Ramos & São Bernardo do Campo \\
\hline Jardins & São Paulo & São Bernardo do Campo & São Bernardo do Campo \\
\hline Trianon & São Paulo & Demarchi & São Bernardo do Campo \\
\hline Jd. Paulista & São Paulo & Reservatórios Billings & São Bernardo do Campo \\
\hline Jd. Europa & São Paulo & Diadema & Diadema \\
\hline Chác. Flora & São Paulo & Piraporinha & Diadema \\
\hline Santo Amaro & São Paulo & Barueri & Barueri \\
\hline Vila Miranda & São Paulo & Alphaville & Barueri \\
\hline Cid. Nitro Operária & São Paulo & Tamboré & Barueri \\
\hline
\end{tabular}

